\title{
Electroencephalography and computerised tomography in vascular and non-vascular dementia in old age
}

\author{
MARGARETA. ROBERTS, A N NE P. M C G E R G E, \\ A N D F. I. C A I R D \\ From the University Departments of Geriatric Medicine and Neurology, \\ Institute of Neurological Sciences, Southern General Hospital, Glasgow
}

SU M MARY Nine normal elderly subjects and 81 patients with dementia have been studied by computerised tomography (CT) and electroencephalography (EEG). There was a broad relationship between slowing of the basic frequency of the EEG and the severity of mental impairment. Localised slow-wave activity was found in $19 \%$ of those with non-vascular dementia and $72 \%$ of those with dementia of vascular origin. The mean size of the ventricles, as determined from CT scans, was larger in the vascular than in the non-vascular group. Within the vascular group it was larger in those without than in those with visible infarcts. There was no relationship in either group between ventricular size and dominant EEG frequency.

The distinction between dementia in old age from vascular disease and that caused by primary neuronal changes was stressed by Roth and Morrissey (1952). Patients with vascular dementia tend to be younger, to have high blood pressure, and to show focal neurological signs, and may have a history of previous stroke. These features are absent in the non-vascular or "senile" group. Tomlinson et al. (1970) have shown the pathological basis for this distinction, but it is less clear whether investigation in life can assist in separating the two groups. The numerous electroencephalographic (EEG) studies of normal and demented old people have been reviewed by Busse and Wang (1965), but in many of them dementia from vascular disease has either been excluded, or not differentiated from that due to other causes. Computerised tomography (CT) can show cerebral atrophy by demonstrating increased ventricular size and sulcal widening, and has largely replaced pneumoencephalography as a safe, non-invasive technique for the investigation of dementia (Fox et al., 1975; Huckman et al., 1975; Roberts et al., 1976; Roberts and Caird, 1976).

Address for reprint requests: Dr F. I. Caird, University Department of Geriatric Medicine, Southern General Hospital, Glasgow G51 4TF, Accepted 16 May 1978
The present investigation represents an attempt to assess the value of electroencephalography and computerised tomography in the investigation of dementia in old age.

\section{Methods}

Ninety patients, 64 of them women, aged 61 to 90 years, who were under the care of the University Department of Geriatric Medicine, were investigated by EEG and CT; informed consent was obtained from the nine mentally normal subjects. A detailed history was obtained, and a neurological examination performed. Mental state was assessed clinically, and simple psychometric tests carried out, as described by Roberts and Caird (1976).

Patients with dementia were classified according to the criteria of Roth and Morrissey (1952) and Slater and Roth (1969). Those with a history of stroke or with focal neurological signs were considered to have vascular dementia, those without such history and signs, but with a slowly progressive history, non-vascular dementia.

The EEGs were classified as suggested by Weiner and Schuster (1956) from the frequency of the dominant rhythm: group I: normal alpha rhythm at 8-13 Hz; group II: beta rhythm of $>13 \mathrm{~Hz}$ (often associated with drug therapy); 
group III: theta rhythm of 4-7 Hz; group IV: delta rhythm of 1-3 Hz. Any persistent localised slowwave (delta) activity was noted, together with its site.

The methods of Roberts et al. (1976) were used to determine the maximum ventricular area on the computerised tomogram from an $80 \times 80$ printout of the cut showing the largest ventricular image. Note was made of the presence of infarcts, visible on the Polaroid prints as low density areas in the substance of the brain.

\section{Results}

There was a trend towards an increasing frequency of slow EEG rhythms (groups III and IV) with increasing severity of mental impairment (Table 1). Nine of 40 patients with non-vascular dementia of moderate or severe degree had EEGs in group IV, and two out of 20 with vascular dementia; no patient in whom dementia was mild, and no normal subject had an EEG in this group. Localised slowwave activity was seen in nine of the 48 with nonvascular dementia $(19 \%)$, and in 24 of $33(72 \%)$ in the vascular group. In the latter, the site of the slow-wave activity usually correlated with the focal neurological signs.

Table 1 EEG findings

\begin{tabular}{|c|c|c|c|c|c|c|}
\hline \multirow[t]{2}{*}{ Mental state } & \multirow[t]{2}{*}{ Number } & \multirow{2}{*}{$\begin{array}{l}\text { Age }(y r: \\
\text { mean } \pm S D)\end{array}$} & \multicolumn{3}{|c|}{ EEG group } & \multirow{2}{*}{$\begin{array}{l}\text { Localised } \\
\text { slow-wave } \\
\text { activity }\end{array}$} \\
\hline & & & $\boldsymbol{I}+$ & $I I I I$ & $I V$ & \\
\hline Normal & 9 & $81 \pm 8$ & 8 & 1 & 0 & 2 \\
\hline $\begin{array}{l}\text { Dementia } \\
\text { non-vascular } \\
\text { Mild } \\
\text { Moderate } \\
\text { Severe }\end{array}$ & $\begin{array}{r}8 \\
20 \\
20\end{array}$ & $\begin{array}{l}80 \pm 7 \\
78 \pm 8 \\
74 \pm 7\end{array}$ & $\begin{array}{l}3 \\
9 \\
5\end{array}$ & $\begin{array}{r}5 \\
7 \\
10\end{array}$ & $\begin{array}{l}0 \\
4 \\
5\end{array}$ & $\begin{array}{l}3 \\
2 \\
4\end{array}$ \\
\hline $\begin{array}{l}\text { Dementia } \\
\text { vascular } \\
\text { Mild } \\
\text { Moderate } \\
\text { Severe }\end{array}$ & $\begin{array}{r}13 \\
12 \\
8\end{array}$ & $\begin{array}{l}77 \pm 4 \\
72 \pm 6 \\
73 \pm 6\end{array}$ & $\begin{array}{l}5 \\
5 \\
1\end{array}$ & $\begin{array}{l}8 \\
5 \\
7\end{array}$ & $\begin{array}{l}\mathbf{0} \\
\mathbf{2} \\
\mathbf{0}\end{array}$ & $\begin{array}{r}10 \\
8 \\
6\end{array}$ \\
\hline
\end{tabular}

Mean ventricular size tended to increase with increasing mental impairment in those with nonvascular dementia, and was greater in those with vascular dementia, particularly those in whom no definite infarct was visible on CT (Table 2, Figure). All five patients in whom the maximum ventricular area was greater than $45 \mathrm{~cm}^{2}$ had vascular dementia without a visible infarct.

Table 3 shows that there was no relationship in either group of patients with dementia between maximum ventricular area and the dominant EEG frequency.

\section{Discussion}

The clinical criteria for the distinction between the two main forms of dementia in old age are clear and provide few difficulties in practice, apart from the possibility that both processes may be present in the same patient. Under these circumstances, vascular dementia is likely to be the clinical diagnosis (Tomlinson et al., 1970). In the present study, the clinical grouping is thought to be realistic. In non-vascular dementia, simple psychometric tests can contribute to the assessment of its severity (Robinson, 1961). In vascular dementia, however, dysphasia may invalidate verbal tests and hemiplegia scores involving mobility or the ability to dress. In this study, therefore, little reliance has been placed on psychometric tests in assessing the severity of dementia, but experience supports the validity of the clinical assessments of severity in both vascular and non-vascular groups.

The dominant frequency of the EEG slows with age, but usually remains within the alpha range (Friedlander, 1958). More normal old people than young have frequencies in the theta range (Obrist, $\mathbb{D}$ 1954; Silverman et al., 1955). In dementia in old $\stackrel{\vec{\Phi}}{+}$ age several studies have shown that with increasing degrees of intellectual impairment, slow dominant frequencies become even more common (McAdam and McClatchey, 1952; McAdam and Robinson, 1957; Obrist et al., 1962). Our findings are inô agreement with this (Table 1); dominant delta? activity was found only in those with moderate or severe intellectual impairment. Localised temporal slow-wave activity is common in normal old age (Busse et al., 1956). Slow-wave activity in other sites has been noted to be considerably more common in dementia of vascular origin (Luce and Rothschild, 1952; Kiloh et al., 1972) than, for instance, in Alzheimer's disease (Gordon and Sim, 1967), and this difference is supported in the present study (Table 1) where there was a reasonable correlation between physical signs, the presence of a visible infarct, and the site of slow-wave activity.

The trend towards increasing maximum ventricular area with increasing intellectual impairment in non-vascular dementia has been described previously (Roberts and Caird, 1976). In the vascular group there is a striking difference between those in whom an infarct was visible on the CT scan and the remainder, who show a much larger mean ventricular size (Table 2). The necropsy measurements of Tomlinson et al. (1970) support this difference, though Corsellis (1962) noted greater cerebral atrophy in non-vascular 


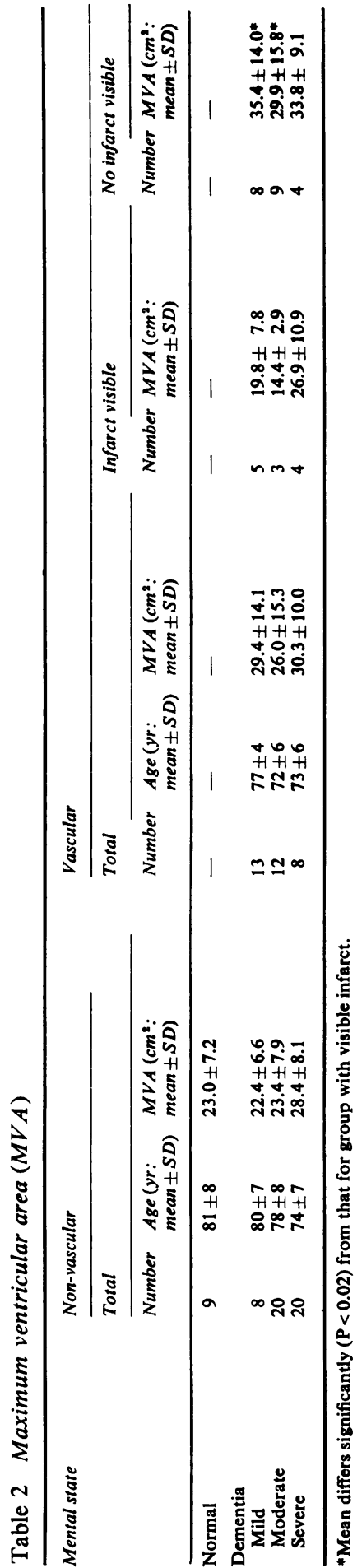

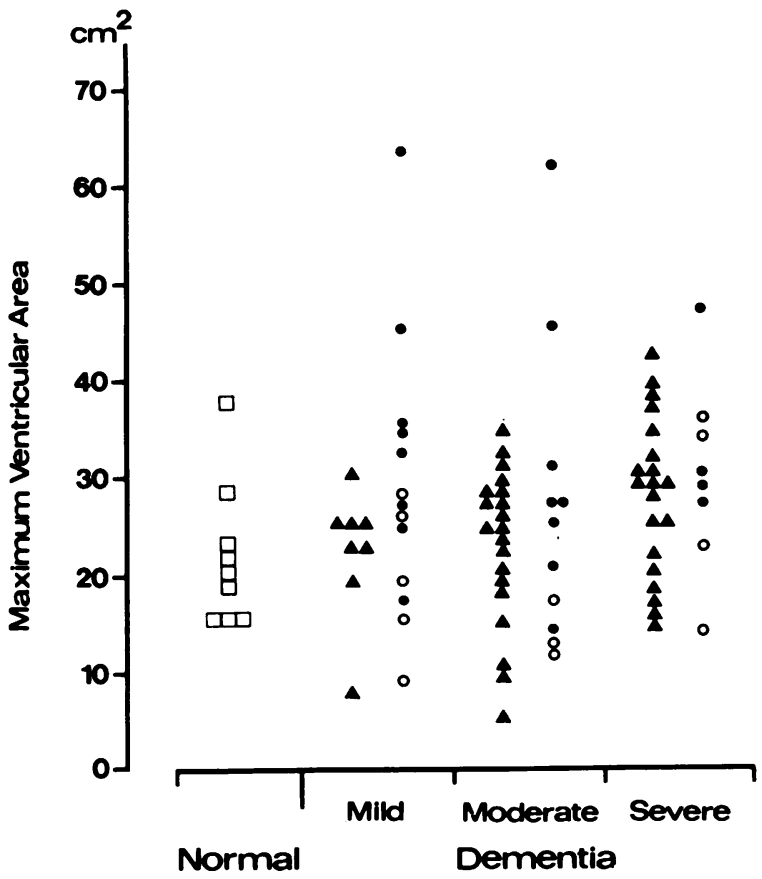

Figure Maximum ventricular area in nine normal elderly subjects and 81 patients with dementia, divided by cause of dementia and presence or absence of visible infarcts in those with vascular dementia. $\square==$ normal; $\Delta$ =non-vascular; $\odot=$ vascular, infarct visible; $=$ vascular, infarct not visible.

Table 3 Relationship between maximum ventricular area $\left(\mathrm{cm}^{2}:\right.$ mean $\left.\pm S D\right)$ and $E E G$ group

\begin{tabular}{llll}
\hline & \multicolumn{2}{l}{$E E G$ group } \\
\cline { 2 - 4 } Dementia & $I+I I$ & $I I I$ & $I V$ \\
\hline Non-vascular & $25.6 \pm 6.9(19)$ & $26.4 \pm 8.1(23)$ & $22.4 \pm 8.8(10)$ \\
Vascular & $28.0 \pm 18.5(11)$ & $28.7 \pm 11.0(20)$ & $27.2 \quad$ (2) \\
\hline
\end{tabular}

Figures in brackets are numbers of subjects.

than in vascular dementia. However, his criteria include widening of the cortical sulci, which cannot yet be quantified accurately on CT scans (Roberts et al., 1976). In vascular dementia without large infarcts, the intellectual impairment is presumably caused by multiple small lacunar infarcts (Hachinski et al., 1974); ventricular dilatation in this condition was described over 70 years ago by Pierre Marie (Fisher, 1965).

In non-vascular dementia, the degree of EEG abnormality and the degree of ventricular dilatation have both been shown to be related to the severity of mental impairment (McAdam and Robinson, 1957; Roberts and Caird, 1976), but suggestions that EEG changes are correlated with ventricular size as shown by pneumoencepha- 
lography (Trowbridge and Finley, 1942; Levin and Greenblatt, 1948; Lundervold et al., 1962) are not supported either by the present study (Table 3 ) or by Stefoski et al. (1976). The fact that EEG changes reflect disordered cortical function rather than loss of cerebral substance makes the lack of any relationship between the two less surprising.

In the present study the presence of localised slow-wave activity related to focal neurological signs is shown to be of value in distinguishing vascular from non-vascular dementia in old age. Computerised tomography can also be of value if infarcts are clearly demonstrable. However, in the great majority of cases of dementia in old age, neither investigation should be regarded as more than corroborative of distinctions based on a clear clinical history and careful neurological examination.

It is a pleasure to thank our colleagues for referring patients for investigation, and the radiologists of the Institute of Neurological Sciences, Glasgow, for their assistance and advice.

\section{References}

Busse, E. W., Barnes, R. H., Friedman, E. L., and Kelty, E. J. (1956). Psychological functioning of aged individuals with normal and abnormal electroencephalograms. I: a study of non-hospitalised community volunteers. Journal of Nervous and Mental Disease, 124, 135-141.

Busse, E. W., and Wang, H. S. (1965). The value of electroencephalography in geriatrics. Geriatrics, 20, 906-924.

Corsellis, J. A. N. (1962). Mental Illness and the Ageing Brain. Oxford University Press: London.

Fisher, C. M. (1965). Lacunes: small, deep cerebral infarcts. Neurology (Minneapolis), 15, 774-784.

Fox, J. H., Topel, J. L., and Huckman, M. S. (1975). Use of computerised tomography in senile dementia. Journal of Neurology, Neurosurgery, and Psychiatry, 38, 948-953.

Friedlander, W. J. (1958). Electroencephalographic alpha rate in adults as a function of age. Geriatrics, 13, 29-31.

Gordon, E. B., and Sim, M. (1967). The EEG in presenile dementia. Journal of Neurology, Neurosurgery, and Psychiatry, 30, 285-291.

Hachinski, V. C., Lassen, N. A., and Marshall, J. (1974). Multi-infarct dementia: a cause of mental deterioration in the elderly. Lancet, 2, 207-209.

Huckman, M. S., Fox, J. H., and Topel, J. L. (1975). The validity of criteria for the evaluation of cerebral atrophy by computerised tomography. Radiology, 116, 85-92.

Kiloh. I.. G., McComas, A. J., and Osselton, J. W. (1972). Clinical Electroencephalography. Third edition, p. 187. Butterworths: London.

Levin, S., and Greenblatt, M. (1948). Electroencephalo- gram in cases with cortical atrophy and ventricular dilatation. American Journal of Psychiatry, 105, 220-223.

Luce, R. A., and Rothschild, D. (1952). The correlation of electroencephalographic and clinical observations in psychiatric patients over 65 . Journal of Gerontology, 8, 167-172.

Lundervold, A., Engeset, A., and Lönnum, A. (1962). The EEG in cerebral atrophy. World Neurology, 3, 226-233.

McAdam, W., and McClatchey, W. T. (1952). The electroencephalogram in aged patients of a mental hospital. Journal of Mental Science, 98, 711-715.

McAdam, W., and Robinson, R. A. (1957). Senile intellectual deterioration and the electroencephalogram; a quantitative correlation. Journal of Mental Science, 103, 819-825.

Obrist, W. D. (1954). The electroencephalogram of normal aged adults. Electroencephalography and Clinical Neurophysiology, 6, 235-244.

Obrist, W. D., Busse, E. W., Eisdorfer, C., and Kleemeier, R. W. (1962). Relation of the electroencephalogram to intellectual function in senesence. Journal of Gerontology, 17, 197-206.

Roberts, M. A., and Caird, F. I. (1976). Computerised tomography and intellectual impairment in the elderly. Journal of Neurology, Neurosurgery, and Psychiatry, 39, 986-989.

Roberts, M. A., Caird, F. I., Grossart, K. W., and Steven, J. L. (1976). Computerised tomography in the diagnosis of cerebral atrophy. Journal of Neurology, Neurosurgery, and Psychiatry, 39, 909-915.

Robinson, R. A. (1961). Some problems of clinical trials in elderly people. Gerontologia Clinica, 3, 247-257.

Roth, M., and Morrissey, J. D. (1952). Problems in the diagnosis and classification of mental disorder in old age. Journal of Mental Science, 98, 66-80.

Silverman, A. J., Busse, E. W., and Barnes, R. H. (1955). Studies in the process of aging; electroencephalographic findings in 400 elderly subjects. Electroencephalography and Clinical Neurophysiology, 7, 67-74.

Slater, E., and Roth, M. (1969). Clinical Psychiatry. Bailliere, Tindal and Cassell: London.

Stefoski, D., Bergen, D., Fox, J., Morrell, F., Huckman, M., and Ramsey, R. (1976). Correlation between diffuse EEG abnormalities and cerebral atrophy in senile dementia. Journal of Neurology, Neurosurgery, and Psychiatry, 39, 751-755.

Tomlinson, B. E., Blessed, G., and Roth, M. (1970). Observations on the brains of demented old people. Journal of the Neurological Sciences, 11, 205-242.

Trowbridge, E. H., and Finley, K. H. (1942). The electroencephalogram and pneumoencephalogram in non-focal neurological disorders. American Journal of Roentgenology and Radium Therapy, 47, 699-702.

Weiner, H., and Schuster, D. B. (1956). The electroencephalogram in dementia-some preliminary observations and correlations. Electroencephalography and Clinical Neurophysiology, 8, 479-488. 